\section{Edycaşãa

\section{Editor \\ Maria Inês Côrte Vitoria PUCRS, RS, Brasil \\ Equipe Editorial \\ Pricila Kohls dos Santos PUCRS, RS, Brasil \\ Marcelo Oliveira da Silva PUCRS, RS, Brasil \\ Carla Spagnolo PUCRS, RS, Brasil Rosa Maria Rigo PUCRS, RS, Brasil}

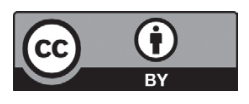

\title{
Interfaces de um intercâmbio de doutorado: formação de professores e experiências relevantes
}

\author{
Interface of a doctoral exchange program: \\ teacher educationand relevant experiences
}

\section{Elane Chaveiro Soares ${ }^{\mathrm{a}}$}

RESUMO: Neste texto apresento a construção de conhecimento proporcionada pelo intercâmbio de Doutorado realizado na cidade de La Plata/Argentina, a partir do convênio entre a Pontifícia Universidade Católica do Rio Grande do Sul (PUCRS) e a Universidade Nacional de La Plata (UNLP)/financiado pela CAPES. Pude estudar por três meses (agosto a outubro/2011) nesta universidade e participar ativamente de quatro importantes atividades realizadas neste período. Primeiro como ouvinte do VIII Encuentro de Cátedras de Pedagogía de

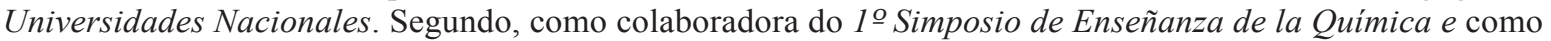
aluna do Seminário de Politicas de Formacion, Currículum e Identidades Docentes ministrado pela professora Ms. Flavia Terigi. E finalmente, como apresentadora de comunicação oral no I Congreso Internacional de Enseñanza de las Ciencias y Matemática y II Encuentro Nacional de Enseñanza de la Matemática.O relatório foi escrito a partir da construção de conhecimento na complexidade vivencial das discussões propostas, do referencial teórico utilizado nesta universidade, do profícuo envolvimento com o corpo docente e discente do Departamento de Ciências Exactas y Naturales da Facultad de Humanidades da UNLP, além da imersão realizada em outra cultura, com outra língua e outros enfrentamentos. O engajamento proposto para a realização deste intercâmbio foi essencial na conquista de aprendizagens relacionadas ao Ensino de Química e à Formação de Professores junto a nossos hermanos. A realização de um Doutorado em Educação pressupõe, dentre outras coisas, a superação de lutas concorrenciais por domínio de espaço e de voz com interfaces cada vez mais entrelaçadas.

Palavras-chave: intercâmbio de doutorado; formação de professores; ensino de química.

ABSTRACT: In this text I present the construction of knowledge provided by a Doctoral exchange program in the city of La Plata/Argentina, from the agreement between the Pontifical Catholic University of Rio Grande do Sul (PUCRS) and the National University of La Plata (UNLP)/financed by CAPES. I studied for three months

\footnotetext{
a Doutora em Educação pela PUCRS. Professor Adjunto III do Departamento de Química da UFMT - Área de Ensino de Química. Pesquisadora do Laboratório de Pesquisa e Ensino de Química - LabPEQ/UFMT. <elaneufmt@gmail.com>.
} 
(From August to October/2011) in this university and I actively participated in four major activities in this period. First as listener of the VIII Encuentro de Cátedras de Pedagogía de Universidades Nacionales. Second, as a collaborator of the 1st Simposio de Enseñanza de la Química and as a student of the Seminar of Politicas de Formacion, Curriculum e Identidades Docentes which wastaught by teacher Ms. Flavia Terigi. And finally, as oral communication presenter in the I Congreso Internacional de Enseñanza de las Ciencias y Matemática y II Encuentro Nacional de Enseñanza de la Matemática. The report was written from the construction of knowledge on experiential complexity of the proposed discussion, from the theoretical framework used in this university, from the fruitful involvement with the teaching staff and students of the Department of Ciências Exactas y Naturales of the Faculty of Humanities of the UNLP, besides the immersion performed in another culture, with another language and other clashes. The engagement proposed to carry out this exchange program was essential in the achievement of learning related to Chemistry Teaching and Teacher Training together with our hermanos. Achieving a Doctorate in Education presupposes, among other things, overcoming competitive struggles of domain space and voice with increasingly intertwined interfaces.

Keywords: doctoral exchange program; teacher education; chemistry teaching.

\section{Doutorado em Educação: uma opção de atuação}

Sem dúvida a educação é um fato - porque se dá. Sem dúvida, é um processo, porque está sempre se fazendo. Envolve pessoas num contexto. Ela mesma sendo contextualizada - onde e como se dá. É uma aproximação desse fato-processo que a pesquisa educacional tenta compreender.

(Bernardeti Angelina Gatti, 2007, p. 14)

E ducação é um fato-processo como afirma Gatti (2007) e a pesquisa em educação, continua a autora, se reveste de características específicas. Isso porque "pesquisar em educação significa trabalhar com algo relativo a seres humanos ou com eles mesmos, em seu próprio processo de vida" (p. 12).

Diferentemente de uma pesquisa que manipula objetos, a pesquisa em educação não pode ser estritamente experimental onde os fatores da situação podem ser controlados. Não podemos fazer pesquisa em educação em laboratórios senão no contexto ou no ambiente onde estes processos se dão.

No Brasil, um profissional das licenciaturas seja da área de exatas, de humanas ou das linguagens, normalmente não encontra dificuldades em realizar a pós-graduação no âmbito da educação. Normalmente, os projetos pedagógicos 
destes cursos contemplam um perfil para o egresso com o desenvolvimento de habilidades de inter-relação e aproximação com o subjetivo do humano. Nos textos destes projetos, nem sempre claros, reside a preocupação com a construção do conhecimento e com o outro na relação ensinar/aprender, como é o caso dos projetos de Licenciatura em Química e Física da UFMT citados abaixo:

... o profissional licenciado em Química deve ter formação generalista, mas sólida e abrangente em conteúdos dos diversos campos da Química, preparação adequada à aplicação pedagógica do conhecimento e experiências de Química e de áreas afins na atuação profissional como educador na educação fundamental e média (PPC QUÍMICA/UFMT, p. 23).

A intenção é formar um profissional capaz de compreender os avanços do conhecimento Químico e demais ciências, que tenha condições de conceber a sala de aula como ambiente de constante pesquisa para melhoria de seu trabalho docente, sendo capaz de promover em seus alunos a construção do conhecimento, apresentando-lhes os avanços da Ciência em seus múltiplos aspectos e implicações. Um profissional que decodifique o conhecimento e a linguagem da área, enquanto educador, e que realize pesquisas no sentido de melhor ensiná-los, utilizando-se da ação-reflexão-ação (PPC FÍSICA/UFMT, p. 40).

Há, porém, ainda hoje, um substrato ideológico, sociológico e político na escolha do campo de atuação. Realizar um Doutorado em Educação nem sempre é concebido como uma oportunidade de contribuir para o desenvolvimento da área específica. Em se tratando de áreas denominadas hard - como a Química, a Física e a Matemática, por exemplo - em detrimento daquelas ditas soft - como Português, História, Geografia etc. - vemos que, a relação impressa continua sendo a de lutas concorrenciais por domínio de espaço e de voz (BOURDIEU, 1983).

As perguntas seguem com poucas variações: O que vale mais, realizar um Doutorado em Educação ou em Química aplicada? O que é mais importante, investigar a formação de professores ou a mutação do vírus? Focar na produção de materiais didáticos ou de novos remédios? Seria mesmo o caso de colocar na mesma balança itens tão diversos como os citados? Ou estamos usando pesos e medidas equivocadas para estatizar um título, ou um campo de pesquisa em detrimento de outro?

Num momento onde a busca pelo pensamento interdisciplinar alimenta os processos de articulação política e organizacional das universidades brasileiras, é importante ressaltar a contribuição da especialização educacional no âmbito do ensino superior. A universidade precisa participar de forma mais ativa e menos dogmática na configuração de um cenário mais inclusivo e globalizado para a educação. 
É preciso compreender que há um sistema educacional intimamente ligado à pesquisa e à extensão e é da universidade que fluem os profissionais que atuarão no ensino, desde a educação infantil à superior. Nas universidades atuam professores que - com formação nos diversos cursos - desempenham a docência nos departamentos e institutos. Sendo assim, a formação profissional para a docência ou sua busca através da pós-graduação não pode ser, ou pelo menos não deveria ser, uma opção e sim uma necessidade. Ensinar é tão importante quanto pesquisar ou fazer extensão, ou melhor, não há que se colocar uma ação e em detrimento das outras, há de se buscar uma complexa atuação e uma maior abrangência de perspectivas.

A preocupação com a atuação docente no ensino superior vem ganhando espaço desde a percepção de que o edital aberto para as universidades, em sua maioria esmagadora, não busca por pesquisadores e sim por professores. Não há, pelo menos de forma explícita, concurso para pesquisador universitário. Se apenas este aspecto fosse realmente levado em consideração, os concursos privilegiariam a formação nos cursos de licenciaturas e não nos cursos de bacharéis, pois a formação docente se dá prioritariamente nos primeiros e não nestes últimos.

Anterior a esta discussão proposta é possível constatar que há uma presença maciça de bacharéis atuando nas instituições de ensino superior (IES) brasileiras, seja nas universidades seja nos institutos públicos ou particulares. Não que estes devessem ser impedidos de exercer adocência, mas que fossem pelo menos orientados a buscar formação complementar para atuar no ensino de forma mais esclarecida.

A partir dessa compreensão e do reconhecimento do impacto social e profissional que um Doutorado em Educação pode provocar no ensino superior - tanto quanto qualquer outro Doutorado - a partir de uma prática pedagógica intencional e sistematicamente planejada, é que sigo relatando as possibilidades de aprendizado encontradas na travessia ${ }^{1}$ do Doutorado em Educação realizado na Pontifícia Universidade Católica do Rio Grande no período de 2009 a 2012. Lá se vão quatro anos desta experiência que oficializou minha formação enquanto pesquisadora da área de ensino de Química.

\footnotetext{
1 Termo que utilizo para significar não apenas um "Pôr de través ou obliquamente", mas uma travessia como a que realiza uma flecha, que transpassa e que enfrenta as resistências, que sofre e que ao mesmo tempo interfere e se deixa interferir. Como em uma de suas possíveis traduções do inglês - toget over - que significa: melhorar, superar, recuperar-se, restabelecer-se. Como quem atravessa um rio e consegue chegar ao outro lado da margem, molhado e às vezes exaurido pela força das correntezas e pela dureza das pedras, mas plenamente contente com a conquista. Como uma vertente influenciadora, revigorante e propulsora de novas investidas e descobertas (SOARES, 2012).
} 


\section{O intercâmbio em si: a cultura, o lugar e os enfrentamentos}

Do que foi apresentado anteriormente ressalto ainda que a busca por um Doutorado em Educação baseou-se na necessidade de ampliar e aprofundar conhecimentos relacionados à prática docente que realizo desde os anos de 1989, quando iniciei minha vida profissional como professora da educação básica atuando,como todo iniciante na docência, nos três períodos escolares, matutino, vespertino e noturno. Com o ingresso na universidade em 1988 e uma expectativa pouco fundamentada sobre o que era ser professora, minha visão era dicotômica em relação à teoria e prática, como se uma sobrepujasse a outra.Eu possuía, além disso, uma visão ingênua da própria profissionalidade docente.

Para não ser injusta com todo o tempo processual da graduação - que foi realizado quase de forma concomitantecom a atuação na profissão docente - da especialização e do mestrado que defendi em 1997 e desde este período até o ano de 2009, quando ingressei no Doutorado em Educação, retifico a importância de cada etapa e de cada enfrentamento, mas deixo para outro texto o relato e as referências a estes processos. São especificidades da formação inicial, compreendidas hoje, como importantes e necessárias.

$\mathrm{Na}$ travessia pelo Doutorado posso afirmar que a maioria das atividades realizadas me proporcionou a tomada de consciência, o exame e a análise dos fundamentos ou das razões que me fizeram caminhar pela pós-graduação (Japiassú, 2006). A reflexão, que inicialmente era interna e propositalmente feita em torno da própria prática, avançou para uma compreensão mais global e significativa das questões relacionadas ao ensino de Química e à formação de professores. Perceber-me neste processo possibilitou-me a construção de um estado de conhecimento mais apuradoemais engajado na possibilidade de um ensino de Química políticamente planejado.

No tempo do Doutorado, muitas oportunidades de aprendizado e reformulação do que já sabia foram-me conferidas. Todas elas relevantes e impulsionadoras de transformações que uma pós-graduação pode provocar como,por exemplo: a saída de um Estado para o outro (de Mato Grosso para o Rio Grande do Sul); a saudade da família, dos três filhos e marido que ficaram em casa, pois que não tínhamos condições à época de colocar a todos no mesmo contexto; a imersão em uma instituição privada muito diferente - em diferentes aspectos da instituição pública na qual obtive toda minha formação inicial (da UFMT para a PUCRS); as aprendizagens proporcionadas pelos créditos disciplinares obrigatórios; a participação em eventos internacionais como forma de ampliar a visão e alargar as fronteiras do conhecimento; a convivência com uma orientadora competente, amorosa e rigorosa - no sentido freireano - e a experiência para a qual dedico este texto: o intercâmbio de três meses na Argentina, mais precisamente no período de agosto a outubro de 2011 na Universidade Nacional de La Plata. 
Do primeiro ao último dia deste intercâmbio, realizado de agosto a outubro de 2011, todas as atividades foram criteriosamente organizadas com o objetivo de obter o máximo de envolvimento e imersão na cultura e na vida acadêmica local.

O contato com outra cultura, outra língua e outros olhares sobre a formação de professores fez-me alimentar algumas certezas - em meio a tantas incertezas - de que não estamos sozinhos na busca por respostas satisfatórias aos embates enfrentados pelos professores em suas salas de aula, pelos formadores, pesquisadores, enfim por todos os envolvidos de alguma forma com a questão da formação de professores.

De início compreendi que estar em outro país, em um intercâmbio, sem obrigações rigidamente preestabelecidas pelo programa, pelo contrário, com uma gama esplêndida de oportunidades, era ao mesmo tempo assutador e instigante. Eu mesma teria que planejar minha atuação e me envolver em atividades relevantes. Vi-me então, no contexto da autonomia, que era ao mesmo tempo, libertadora e rigorosa no sentido de que eu precisa cumprir os deveres mas que tinha à minha frente a possibilidade da criatividade e da inventividade para criar o roteiro mais adequado para esse período.

Decidi que, além de participar ativamente de todas as atividades acadêmicas, eu iria conhecer o complexo histórico da cidade de La Plata, vivenciar sua cultura e relacionar-me com as pessoas do local.Nesta imersão cultural, aprender um pouco mais do espanhol foi uma condição quase involuntária. Matriculei-me na Escuela de Lenguas e vivi momentos de muita diversidade com colegas do Japão, da Irlanda, da Inglaterra, da Alemanha e da própria Argentina.

A língua espanhola fluia na medida em que dialogava com os colegas e professores da universidade, com as pessoas nas ruas, nos mercados, cafeterias e restaurantes por onde passava. A mente, por vezes, clamava por ouvir um bom portugues, mas a única possibilidade era falar com a familia por telefone ou por internete pois que nesta oportunidade, não tive nenhum colega brasileiro(a) para me acompanhar na jornada.

Aprendi que La Plata foi fundada em 19 de novembro de 1882, para servir de capital da província, após Buenos Aires ter-se tornado um distrito federal. Esta capital completou em 2012, 130 anos de existência. É conhecida como a cidade das diagonais. Com um mapa nas mãos, é praticamente impossível alguém se perder por lá. Toda a cidade foi milimetricamente desenhada, contanto com esquinas bem sinalizadas, numa perspectiva quadrada.

Suas ruas são planas e arborizadas e um dos incovenientes que encontrei para transitar por ela - além do frio de $2^{\circ} \mathrm{C}$ no mês de agosto - foi o fato de que a cidade não possui um sistema de aluguel de bicicletas, o que facilitaria o trânsito de quem não tem automóvel, principalmente de estudantes.

A chegada da primavera, no mês de setembro é uma grande festa em toda a Argentina. O dia 21 de setembro feriado nacional - é celebrado com shows ao ar livre, passeios pelas praças que neste época estão bastante floridas, sorvetes e muita alegria. Tive a grande satisfação de presenciar a explosão de cores nos canteiros repletos de flores. 
Alguns lugares históricos e turísticos me surpreenderam. O primeiro foi a Catedral Metropolitana de La Plata "Inmaculada Concepción" - uma construção magnífica, muito bem conservada, encravada no centro da praça Moreno em La Plata - inaugurada em 19 de novembro de 1932.

O segundo foi o Observatório Astronômico, que teve suas construções iniciadas em novembro de 1883. De lá, foi possível capturar uma bela imagem da Lua e desfrutar de uma aula de História da Astronomia ministrada por um monitor quando visitei o observatório, incluindo relatos de como aquele imenso telescópio chegou em La Plata.

Outros lugares também me chamaram a atenção, tanto pela exuberância quanto pela conservação, como o Jardin Zoológico e Bontânico de La Plata, fundado em 1907 e o Museo de Ciências Naturais, fundado em 1888. Este último com mais de 2.000.000 de objetos em sua coleçao e apenas uma parte em exposição. Mesmo assim, seu tamanho surpreende por ser o maior da América Latina. Pesquisadores do mundo inteiro podem ser encontrados em seu interior realizando as mais diversas pesquisas.

No destaque às atividades acadêmicas, trago para este texto, o relato de apenas quatro das muitas e intensas experiências proporcionadas por este intercâmbio. Foram aprendizagens únicas e valiosas que produziram maior significado à pesquisa em andamento.

\section{As atividades acadêmicas do intercâmbio}

Na medida em que fui aprendendo a me deslocar pela cidade, garantindo inclusive as idas e vindas de Buenos Aires - a partir de uma viajem de ônibus com duração de mais ou menos 45 minutos - fui também garimpando eventos, encontrando bibliotecas públicas e transitando mais livremente pelos prédios da universidade na cidade de La Plata.

Da primeira atividade - VIII Encuentro de Cátedras de Pedagogía de Universidades Nacionales, realizado de 8 a 10 de agosto de 2011 - destaco a preocupação com a formação pedagógica dos professores nas mais diversas áreas do conhecimento. Uma palavra-chave, pronunciada na maioria das discussões durante o evento foi identidade docente. Havia uma busca pela concretização de ações que superassem o discurso, com propostas que apontando de forma mais significativa, o lugar que a pedagogia deveria ocupar na formação de professores. E, neste evento, pude perceber que havia - ainda que timidamente - indícios de organização sistematizada dessa temática voltada para a área das Ciências Química, Física e Biologia.

A preocupação com o lugar da pedagogia na formação docente perpassou inclusive pelas questões relacionadas ao ensino de Ciências nas séries iniciais. Tais situações são também, ainda hoje, problematizadas pela educação no Brasil. A América latina não está aquém do embate sobre quem deve ensinar Ciências - o professor de Biologia ou o professor de Química - ou o que ensinar de Ciências nos diversos níveis de educação. 
Ayala, Romero e Turpín (2011), que apresentaram comunicações orais neste evento, ressaltaram a resistência que os alunos da Universidad Nacional Del Nordeste, Argentina, do curso de formação de professores da Faculdade de Ciências Exatas e Naturais e do Ambiente, possuíam, frente aos assuntos pedagógicos. Elas consideraram que isto se devia a uma concepção positivista do conhecimento científico, que traz a ideia de que para ensinar basta saber a disciplina. Segundo as autoras, um grande esforço no sentido de repensar o estágio curricular docente estava sendo empreendido na busca de responder o porquê e para que, saber pedagogia.

Elias (2011), ao trazer alguns aportes para a construção de uma identidade docente mostrou a preocupação com a formação inicial. Para ela,

a pedagogia constitui um objeto de conhecimento próprio de seu campo de estudos, a formação pedagógica dos professores que vão atuar nas escolas ensinando a jovens e crianças diferentes conteúdos culturais adquire um significado distinto e obriga a considerar o caráter explicativo da pedagogia e seu potencial como orientadora das práticas educativas (tradução nossa).

A autora afirma ainda que "aqueles que se preparam para ensinar diversas matérias na escola secundária requerem da formação pedagógica uma aproximação que os conecte diretamente com seu futuro desempenho como professores". Compreende-se a partir desse relato, que a disciplina de Fundamentos da Educação, que é responsável por desenvolver os conteúdos da pedagogia e os primeiros tópicos do trajeto de formação docente de quase todos os professores que estudam na Universidade Nacional de La Plata, tem uma proposta que concebe a matéria em duas dimensões. Por um lado, com um campo de estudos acadêmicos, com valor em si mesmo, que aporta as ferramentas intelectuais necessárias para a análise crítica e a compreensão da problemática educativa em toda a sua complexidade. O que para a autora, contribuía para que os estudantes situassem as práticas educativas em seu contexto social, histórico e político mais amplo e considerassem os fins a que elas servem.

Em uma segunda dimensão, estava a constituição de um espaço privilegiado para examinar as possibilidades políticas, morais e sociais alternativas que tais práticas poderiam assumir e começar a elaborar posições pessoais sobre educação.

A preocupação com a construção de uma identidade docente não era privilégio só dos argentinos. Sem dúvida é um tema que preocupa todos os que lidam com formação docente. Vemos que ainda hoje, a temática é perseguida por pesquisas e cada vez mais são inferidas questões de profissionalidade docente, mais especificamente relacionadas ao desenvolvimento profissional docente (MARCELO GARCIA, 2009). 
Ser professor não é simplesmente uma questão de ser ou não ser; passa por decisões complexas que vão desde as concepções iniciais sobre a docência trazida por cada um dos ingressantes nos cursos de formação inicial até a escolha e o desenvolvimento de um currículo que leve em conta a epistemologia de partida - aquele conhecimento que levamos para a graduação - e que possibilita a construção de uma identidade profissional.

A segunda atividade - 1 Simposio de Enseñanza de la Química -foi realizada no dia 17 de setembro de 2011 com o propósito de gerar um espaço de reflexão e debate entre docentes, graduados, investigadores, estudantes e outros profissionais vinculados ao ensino de Química nos distintos níveis do sistema educativo.

O evento contou com a participação de especialistas argentinos em conferências e a realização de uma mesa redonda, pontuando problemas atuais no ensino, as linhas de investigação em curso e as possíveis respostas às questões propostas.

Foram constituídos grupos de trabalho entre professores, especialistas e graduandos que tinham como objetivo, intercambiar os debates e as reflexões dos participantes, elaborando um diagnóstico e uma proposição em torno dos eixos de interesse da comunidade educativa.

Neste evento, entrar em contato com os professores formadores e alunos da graduação em Química da UNLP e de outras universidades próximas, permitiu-me compreender melhor o sistema educacional argentino, dentro do que resolvi chamar de aproximações e distanciamentos ao sistema brasileiro de ensino. Questões como:ausência de laboratórios e de materiais específicos para a realização de experimentos foi destaque nas discussões, além da tentativa de trabalhar por área de conhecimento e não por disciplina. Este último aspecto foi considerado o mais difícil, por conta da alta carga horária de trabalho dos professores e a formação inicial compartimentada ainda presente na graduação. Uma realidade muito próxima da vivida pelos professores brasileiros.

Participar deste evento, só foi possível pelos contatos que realizei com a coordenação do curso de Profesorado em Química no Departamento de Ciencias Exactas y Naturales de la Facultad de Humanidades y Ciencias de la Educación. Fui a este departamento para conhecer, primeiro as pessoas que faziam parte dele e consequentemente me inteirar da dinâmica de formação de professores na UNLP. Pedi também à coordenação que me permitisse ser assistente/observadora de algumas aulas ministradas no curso, o que foi prontamente aceito por duas professoras de Didática das Ciências ou como está no currículo, Didática Específica I e II. Com isso pude constatar que a evasão nos cursos que formam professores, assim como no Brasil, também é bastante acentuada nesta universidade.

A terceira atividade, o Seminário de Politicas de Formacion, Currículum e Identidades Docentes abordou as relações entre o processo de constituição histórica do currículo escolar e a configuração do trabalho docente. Para a professora Ms. Flavia Terigi que ministrou o seminário, a classificação do saber é o princípio organizador de todo o sistema educativo ao longo da história e tende a fortalecer-se à medida que avança para os níveis superiores, mas, 
por diversos fatores, está atenuado nas últimas décadas. Foi possível constatar em alguns casos que o currículo, por seus propósitos formativos, inclui campos de saberes diferentes aos da tradição acadêmica, e estão respeitando a classificação do saber e gerando, em poucos anos, um padrão de estabilidade curricular. A este princípio de classificação se acrescentam a formação e a designação dos docentes por especialidade e também as formas de organização escolar que promovem o trabalho individual.

No mês de novembro de 2011, retornei à Argentina, desta vez para a cidade de Tandil, a fim de apresentar uma comunicação oral no I Congreso Internacional de Enseñanza de las Ciencias y Matemática y II Encuentro Nacional de Enseñanza de la Matemática realizado de 8 a 11 de novembro de 2011. Este trabalho versou sobre a metodologia de estudo de caso do tipo etnográfica baseada em Marli André (1995) utilizada na pesquisa de Doutorado. Nesta oportunidade, pensar na metodologia enquanto princípio que gerou credibilidade dos resultados obtidos dentro, e depois fora do ambiente acadêmico fez com que a pesquisa começasse a ser pensada na perspectiva do social.

Com Gatti (2007, p. 38) aprendi que, para que um conhecimento de pesquisa seja tomado como relevante e socialmente aceito, deve carregar certa abrangência, nível de consistência e foco de impacto, aderência ao real além de tocar em pontos críticos e concretos. Para que isso seja minimamente alcançado é preciso que haja consistência metodológica e possibilidade de inserção nas discussões políticas educacionais.

Considerando que todas estas atividades fizeram parte de um roteiro escrito e vivenciado no processo e que partiram dos anseios da pesquisa em andamento que buscava compreender a epistemologia da Prática Pedagógica do Professor de Química, e ainda, que foram buscadas de forma voluntária por esta pesquisadora, posso argumentar que as experiências vividas durante o intercâmbio de Doutorado acrescentaram uma visão ampliada de pesquisa em educação e de suas interfaces culturais e sociais.

Todos estes momentos tornaram a experiência do intercâmbio um catalisador para novas investidas em pesquisas internacionais, bem como, para aproximar-me de universidades latino-americanas e tornar a visão de graduação e de pós-graduação muito mais atrativa.

\section{Conclusão}

Este intercâmbio de Doutorado, realizado na cidade de La Plata, proporcionou-me uma vivência enriquecedora em torno do tema formação de professores de Química. Foi possível em cada um dos eventos, compreender minimamente a trama epistemológica do pensamento, das ações e das proposições que subsidiam os educadores argentinos.

Do primeiro ao último evento, minhas observações foram entremeadas pela convivência com alunos e professores do Departamento de Ciências Exactas y Naturales da Facultad de Humanidades no curso de Bacharelado em Química 
da Universidade Nacional de La Plata (UNLP). Senti-me plenamente acolhida por toda a equipe de professores do Departamento de Química, bem como pelos funcionários da própria universidade.

O contato com outra cultura, outra língua e outros olhares - na diversidade da América Latina - com foco na formação de professores, fez-me alimentar uma certeza - em meio a tantas incertezas - de que não estamos sozinhos na busca por respostas satisfatórias aos embates enfrentados pelos professores em suas salas de aula, pelos formadores nas academias, pesquisadores, enfim, por todos os envolvidos de alguma forma com a questão da formação de professores.

Gatti (2007, p. 60) afirma que um pesquisador só pode ser imaginativo se tiver um bom estofo teórico, uma ampla cultura bibliográfica na área em que trabalha, além de experiência pelo contato com os problemas relacionados à sua temática. Sendo assim, considero que as interfaces do intercâmbio de Doutorado realizado revelaram uma gama de experiências relevantes, de situações profissionais e acadêmicas que alimentaram a imaginação na busca por compreender a Prática Pedagógica do Professor de Química.

Ir à Argentina para mirar as possibilidades enriqueceu a temática relacionada à epistemologia da prática, ampliou o repertório teórico e forneceu lentes novas para a concretização do Doutorado em Educação, bem como, possibilitou o desenvolvimento de uma nova perspectiva do que seja cidadania global.

Senti falta, no entanto, de uma maior inserção no âmbito da pesquisa propriamente dita realizada na UNLP. Por conta disso, não consegui estabelecer maiores laços com a universidade de La Plata. No entanto, participei de processos de envio de graduandos da licenciatura da UFMT para realizar períodos de intercâmbio na América Latina por acreditar que todo o processo gera experiências relevantes para a formação inicial de professores.

\section{Referências}

AYALA, M. E.; ROMERO, M.; TURPÍN, L. M. La pedagogía en la formación de profesores de Ciencias exactas y Naturales. Una resistencia que persiste, Anais do Encuentro de Cátedras de Pedagogía de Universidades Nacionales Argentinas - Teoría, formación e intervención en Pedagogía, 8 a 10 de agosto de 2011.

ANDRÉ, M. E. D. A. de. Etnografia da Prática Escolar. Campinas, São Paulo: Papirus, 1995.

BOURDIEU, P. Sociologia. São Paulo: Ática, 1983.

ELIAS, M. E. Aportes para la construcción de una identidad docente. Anais do Encuentro de Cátedras de Pedagogía de Universidades Nacionales Argentinas - Teoría, formación e intervención en Pedagogía, 8 a 10 de agosto de 2011.

GATTI, B. A. A construção da pesquisa em educação no Brasil. Brasília: Liber Livros Editora, 2007.

JAPIASSÚ, H. Dicionário Básico de Filosofia. 4. ed. atual. Rio de Janeiro: Jorge Zahar, 2006. 
MARCELO GARCIA, C. Desenvolvimento Profissional: passado e futuro, Sísifo - Revista das Ciências da Educação, n. 08, p. 7-22, jan.-abr. 2009.

SOARES, E. C. Prática Pedagógica do Professor de Química e o estudo de caso do tipo etnográfico: uma metodologia em questão, Actas del I Congreso Internacional de Enseñanza de las Ciencias y la Matemática - ICIECyM. II Encuentro Nacional de Enseñanza de la Matemática. 1. ed. Tandil: Universidad Nacional del Centro de la Provincia de Buenos Aires, 2011. E-Book. p. 671.

Recebido em: abril/2016

Aceito em: novembro/2016

\section{Endereço para correspondência:}

Elane Chaveiro Soares

Rua D, lote 39, Q 10 - Bairro São Roque

78050608 Cuiabá, MT, Brasil

<elaneufmt@gmail.com> 